\title{
On thinking of rewarding the dental team this Christmas
}

\section{S Hancocks, OBE*}

It's been a good year in the practice. Against the odds I know, but a good year none-the-less and I thought I might splash out a little at this festive time and send members of the team some substantial token of my esteem. Hampers came to mind...

Hampers seemed somehow appropriate to celebrate the good things in life. They are always so deliciously presented, oozing luxury from the catalogue's smooth, glossy colour pages or simmering invitingly from the Sunday supplement pull outs, pandering to our most intimate of extravagances. The purveyors of such tracklements, for 'retailers of goods' in no way sufficiently describes provenders of such prime morsels, know their business well.

The containers themselves speak of finer times and aspirational lifestyles. Woven in wicker colours of substantial earth-brown, rustic clay or the jauntier leitmotiv straw harvest, they sport tooled leather straps, hunky buckles and sturdy hinges. Their names too are redolent of a more genteel way of life. The Clarendon Selection, the Randolph Range, a Seasonal Miscellany of Moncrief, the Vermont Variety Basket, all laying claim to a heritage of taste and refinement so fully deserved at Christmas. None of which even begins to describe the glory of the contents.

So, for my associates, I thought the finest 'British Wimpole' was only good enough; a handsome Champagne cru, vintage Clarets and a light Chardonnay set the scene to complement a truly luscious lunch. Hand plucked Norfolk turkey, glazed with Border's gathered heather honey, drizzled with Cumbrian cranberry jus and roasted in a genuine Wiltshire charcoal oven. Stuffed with apple and chestnut compote and presented on a Cornish hand-thrown ceramic carving dish this poultry of distinction would be fit to grace any festive table. Hams, tongues, pates, potted meats and venison terrine. Puddings steaming with plumpest fruit and flickering with bluetongued brandy flames. Mince pies and deep-burnt coffee. Hmm!

The hygienist undoubtedly deserves a delivery of the 'Queen Anne Equipage'. Assembled for the lady on the move, this quintessential collection of teatime favourites includes perfumed infusions from around the world, teas from the orient, cakes and confections from the ovens of continental Europe, conserves and chutneys set with the fragrant promise of seasonallycaptured aromas, spiced shortbreads from the Lochs, preserved cumquats and frosted grapes from the orchards and vines of the globe. Tastefully packed into a hand-crafted, heavy duty hessian Gladstone (subsequently useful year-round for conveying all manner of discrete personal items) an array of sweetmeats to astound the senses. Perfect.

I settled on nothing less than the 'Cavendish Christmas Chocolate Cascade' for the dental nurses. Everything in choco-

\section{The Clarendon Selection,} the Randolph Range, a Seasonal Miscellany of Moncrief, the Vermont Variety Basket...

late. Bars of chocolate. A gaggle of teddy bears, in chocolate. A 'snowstorm' style nativity scene complete with manger, shepherds, wise men and assorted beasts all of whom, as the glass dome is shaken, get covered in, yes, chocolate powder. Several boxes of chocolate. A fully matured, chocolate covered Brie. Chocolate mints. Topped off with novelty chocolate oven gloves and all exquisitely contained in a large, dark chocolate hamper. Plus cocoa.

Not forgetting the receptionist for whom a 'Blandford Bohemian Buffet' is surely the order of the day. Artistically arrayed in a peasant painted tin box lined with vividly pigmented rags and torn table linen of a bygone age comes a tumble of fascinating fin-

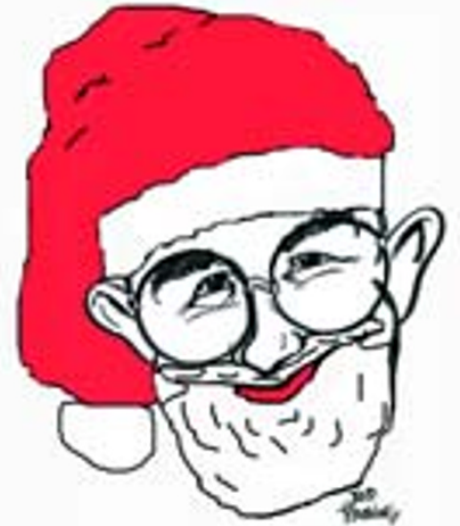

ger foods, light snacks and gourmet sandwiches. Caramelised sausage rolls, truffletrimmed pork pie pieces, Morello cherry quiche sticks and epicurean crisps with various exotic dips vie with clotted fudge waffles and marmalade mint thins for afters. A longer lunch hour than usual this December 25th I predict!

What better end to a busy-fingered year for the trusty technician than the 'Welbeck Winter Wassail'? Presented in a large, selfsealing plastic container to guarantee freshness, the draw-strings of a genuinely artisan-sewn, double stitched canvas-effect duffle bag open to reveal a festive feast. Puddings, pies and pasties linger only long enough to be tantalisingly washed down with lashings of ale and porter. And all surrounded by generous handfuls of nuts from far-flung shores. Tankards to the fore.

Indeed a fine selection for a deserving team. Turning languidly to the order form I tot-up the seasonal sum to find that the total reaches...£oh.dear..., that much. Then, bother. My eye lights upon the one stipulation to which my delayed generosity has blinded me. The absolutely, un-negotiable final date for orders to be guaranteed delivery before Christmas has passed but a day ago. Oh well, maybe next year.

But, humph, what now? Back to the MatS tokens I suppose. Pity really, cooks unpacking the fare, butlers polishing the giant mahogany tables in preparation, the local urchins singing carols through the frosty keyhole of the holly-wreathed front door. Never mind, the tokens usually go down well and after all it is the thought that counts. And I was thinking of them. Must order earlier next year.

Merry Christmas and a Hamper New Year!

* Stephen Hancocks is Commissioning Editor of the BDJ 